\title{
Foetal Position: Can It Be Used to Predict the Sex of Unborn Baby?
}

\author{
Mbaabu G. Limungi1 , Consolata Kirigia ${ }^{2 *}$ (D) \\ ${ }^{1}$ Nursing Department: Kenya Medical Training College, Lodwar Campus, Lodwar, Kenya \\ ${ }^{2}$ School of Nursing: University of Embu (UoEm), Embu, Kenya \\ Email: ${ }^{*}$ consolatakirigia@gmail.com
}

How to cite this paper: Limungi, M.G. and Kirigia, C. (2020) Foetal Position: Can It Be Used to Predict the Sex of Unborn Baby?. Open Journal of Obstetrics and Gynecology, 10, 1441-1448.

https://doi.org/10.4236/ojog.2020.10100132

Received: October 2, 2020

Accepted: October 24, 2020

Published: October 27, 2020

Copyright $\odot 2020$ by author(s) and Scientific Research Publishing Inc. This work is licensed under the Creative Commons Attribution International License (CC BY 4.0).

http://creativecommons.org/licenses/by/4.0/

(c) (i) Open Access

\begin{abstract}
Sex is used to define the biological categorization of a human being as either a male or female. Globally, most of the pregnant women have expressed desire to know the sex of their babies prenatally. To determine sex of the baby before birth, both traditional and modern sex prediction methods have been used. The study aimed at answering the question; can foetal position and sex be related? If so, can it be used to predict the sex of the baby? Analytical perspective utilizing quantitative approach was conducted in a Referral County Hospital to collect data from a sample size of 340 women who were admitted in labour. Selection was done through convenience sampling method. Data were cross tabulated to determine variable frequencies and establish the association, while chi-square was used to test the study hypothesis. Overall results revealed statistically significant relationship between foetal position and sex of the baby $(\mathrm{P}=0.001)$. Majority of female neonates $(74.4 \%)$ had adopted right occipital anterior, while most of male neonates $(57.4 \%)$ had adopted left occipital anterior. It follows then, that sex of the baby may be related to the foetal position. This knowledge may be used by the midwives to predict the foetal sex for the women who may not afford ultrasound scan. Further research may be necessary in a different setting.
\end{abstract}

\section{Keywords}

Foetal, Position, Predict, Sex, Unborn Baby

\section{Introduction}

Sex is the biological categorization of a human being as either a male or female [1]. Globally, pregnant women have always sought to know the foetal sex, with many expecting couples having speculation about foetal sex [2]. Most of the 
pregnant women have expressed desire to know the sex of their babies prenatally [3]. At least $58 \%$ of pregnant women desire to have the foetal sex disclosed to them during ultrasound scan [4]. The desire is even higher especially among some parts of the world where there is stronger preference for a particular sex [5]. In such countries, especially where the ultrasound services are freely offered, it is a "norm" for pregnant women to ask for disclosure of the unborn baby [3]. In Sweden, up to $57 \%$ of pregnant women request to know the foetal sex with up to $46 \%$ of them asking the midwives [6]. In Karachi Pakistan up to $31.4 \%$ of pregnant women wanted to know the foetal sex [7]. Though majority of the women who may need to know about the foetal sex, are women with only one child (62\%), even first timers have expressed desire to know [4]. This may be due to many influencing factors such as pressure from the husband or relatives [5].

In sub-Saharan Africa, there is scanty documented literature on the women who may desire to know the sex of their unborn babies. However, the demand by pregnant women for sex determination during ultrasound is just like in any other part of the world [5]. In Nigeria, majority of expectant women request for ultrasound with a view of determining foetal sex [8]. Up to $94 \%$ of pregnant women would want to know the sex of their babies during obstetrical ultrasound scan, while $5.5 \%$ of the couples are satisfied with whichever sex of their babies and therefore not interested in knowing the sex prenatally [9].

In Kenya, the number of pregnant women who want to know the sex of the baby they are expecting is on increase. Opinion by gynaecologists in Nairobi is that at least $50 \%$ of expectant women visiting them ask to know the sex of their babies. The request to know the sex is even higher among the career women who just want to have a boy and a girl as the only two children they want. Other reasons why women may request to know sex of the baby they expect is pressure to "produce" the opposite sex [10].

It is of great importance to know the sex of baby before birth [11]. Though, some of the pregnant women may need to know the sex of the baby due to curiosity, majority need to know the foetal sex as a measure to prepare for its birth by purchasing the requirement for the baby based on the identified sex [7]. Beside, knowledge on foetal sex improves the relationship between the woman and her future baby [12]. Others may seek to know the foetal sex to "confirm" that they are expecting the "desired" sex. This is because failure to get the desired sex may be considered as "sex infertility" and it is a cause of polygamy practices especially in African society. Therefore they need to be prepared psychologically [13].

Prediction/determination of foetal sex is done using both traditional methods and modern technologies. The technology is highly used especially in developed countries where women may know the sex of the child initially even before conception by help of modern technology in choosing the sex they want [3]. However, these technologies have both the associated risk and cost implication and 
some of them cannot be used for determination of sex alone [4]. On the other hand, traditional methods may not be totally relied upon due to their reduced chances of accuracy. This can have negative impact on the life of woman especially on the event of giving birth to "unexpected" sex. Some women get intense psychological torture to extent of denying their born babies. Others have accused midwives of exchanging their babies after birth by giving them babies who are not of their desired sex hence attracting medical legal action.

Use of ultrasound has been cited as the most embraced technology with accuracy of about $90 \%$ [8]. This mostly benefits expectant women in developed countries where such services are offered freely. In developing countries this important technology has remained unaffordable to some women and especially those who live in some parts of sub-Saharan Africa where resources are limited [9]. To such women, they lack a reliable sex prediction test as they only have the option of relaying on tradition methods whose accuracy is not known.

Therefore, the purpose of this study was to answer the question, can foetal position and sex be related? If so, can it be used to predict the sex of the baby?

\section{Research Questions}

1) What is the relationship between foetal position and sex of the baby?

2) What is the extent to which foetal position can be used to predict the sex of the baby?

\section{Study Objectives}

1) To identify the relationship between foetal position and sex of the baby.

2) To determine if foetal position can be used to predict sex of the baby.

\section{Hypothesis}

There is no significant relationship between foetal position and the sex of the baby.

\section{Materials and Methods}

\subsection{Study Design, Setting and Population}

This was analytical prospective study based on observational method, conducted at Lodwar county referral hospital in Turkana County Kenya. It involved pregnant women who were in labouring process within maternity unit.

\subsection{Sample Selection and Sample Size}

Cochran formula was used to calculate sample size. In a population that is less than 10,000, Cochran formula can be used to determine the ideal sample size [14]. Therefore in this study a desired sample size of 340 was drawn from the study population of 3000 pregnant women who were in laboring process. Convenience sampling method was used to recruit the study participants.

\subsection{Inclusion Criteria}

Eligibility for inclusion in the study was based on the stage of labour, foetal position and mode of delivery. Any woman who was in first stage of labor with foetal 
position being right occipital anterior (ROA) or left occipital anterior (LOA) and delivered within the maternity unit was included in the study regardless of the mode of delivery (spontaneous vertex delivery or caesarean section).

\subsection{Data Collection Tools}

Data was collected using observation check list which had been structured by the researcher to collect relevant data for the study. Such data included the position of the foetus and the sex of the baby after delivery. The tool therefore had five columns which were intended to capture the serial number (to ensure that the number of the study participant were adequate sample size), Right Occipital Anterior position (ROA), Left Occipital Anterior position (LOA), Male and Female (sex of the born baby).

\subsection{Data Collection Process}

Data were collected every two days in a week for a period of four months prospectively. This was determined by the number of women who were in labour. Assessment of foetal position was done through abdominal palpation by both the primary midwife and the researcher, to be sure that the correct position of the foetus was identified before charting in the check list. After delivery, the sex of the delivered baby was observed and noted in the checklist against the already identified foetal position.

\subsection{Data Analysis and Presentation of Findings}

Statistical package for the social sciences version 21 was used to analyze the data. Cross tabulation was used to predict the sex of the baby, by comparing frequencies of the foetal position and Frequencies of actual sex of the baby. Hypothesis was tested using chi-square with a set study significance level of $<0.05$ (that is probability of less than 0.05 ).

\subsection{Ethical Consideration}

Research principles were applied at all levels before, during and after collection of the data. This included seeking for permission from the relevant authorities before data were collected.

\section{Results}

The study involved 340 participants (Table 1) from an estimated population of 3000 pregnant women. The results were analysed and presented as shown below. The study noted that the percentage of women who delivered male neonates was slightly higher than those who delivered female neonates. Male neonates were $51.8 \%$ compared to female neonates who were $48.2 \%$. Besides, Most of the babies who were born had adopted right occipital anterior position (ROA) in utero (57.9\%), while $42.1 \%$ of the babies had adopted left occipital anterior position (LOA). Females were majority of the babies who had adopted right occipital an- 
terior position $(61.9 \%)$, compared to males who were $38.1 \%$. On the other hand, males were majority of the babies who had adopted left occipital anterior position $(70.6 \%)$, compared to females who were $29.4 \%$. majority of female neonates(74.4\%), had adopted right occipital anterior, while male neonates were the majority (57.4\%) who had adopted left occipital anterior.

The chi-square test revealed a chi-square value of 35.176 , and a significance level of 0.001 , which is less than the significance level of $<0.05$ set in this study (Table 2). The study therefore has revealed a significant relationship between foetal position and sex of the baby, hence rejected the null hypothesis which stated that there is no significant relationship between the foetal position and sex of the baby.

\section{Discussion}

The study aimed at identifying the relationship between foetal position and sex of the baby so as to determine if foetal position can be used in predicting sex of the baby.

The study has suggested that among all babies who were delivered at the facility, males were slightly more with $51.8 \%(\mathrm{n}=340)$ against females who were $48.2 \%$. While it has been argued that the number of females is higher than males in the world, this study has suggested the other way round. On the other hand,

Table 1. Position of the foetus * sex of the baby cross tabulation.

\begin{tabular}{rcccc}
\hline & \multicolumn{2}{l}{ Count } & \\
\hline & ROA & \multicolumn{2}{c}{ sex of the baby } & Total \\
\cline { 3 - 4 } Position of the foetus & LOA & 75 & 122 & 197 \\
Total & & 101 & 42 & 143 \\
\hline
\end{tabular}

Table 2. Chi-square tests.

\begin{tabular}{cccccc}
\hline & Value & df & $\begin{array}{c}\text { Asymp. Sig. } \\
(2 \text {-sided })\end{array}$ & $\begin{array}{c}\text { Exact Sig. } \\
(2 \text {-sided })\end{array}$ & $\begin{array}{c}\text { Exact Sig. } \\
(1 \text {-sided })\end{array}$ \\
\hline Pearson Chi-Square & $35.176^{\mathrm{a}}$ & 1 & 0.001 & & \\
Continuity Correction ${ }^{\mathrm{b}}$ & 33.884 & 1 & 0.000 & & \\
Likelihood Ratio & 35.984 & 1 & 0.000 & & 0.000 \\
Fisher's Exact Test & & & & & \\
Linear-by-Linear Association & 35.073 & 1 & 0.000 & & \\
N of Valid Cases & 340 & & & & \\
\hline
\end{tabular}

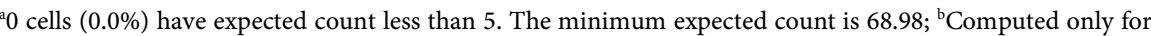
a $2 \times 2$ table. 
the finding concurs with [15] that male birth is biased in every country with a ratio of 105 males per 100 females. The reason for this biasness has been associated with selective abortion and sex determination before conception. Our argument is that not all women have access to these technologies to assist them in sex determination before conception. This is even true especially in Sub-Saharan Africa where such technologies are expensive and not affordable [9].

Besides, preconception care is never offered in many of the developing countries. In addition, selective abortion is regarded as a crime and is not permitted by law in many countries and especially Kenya [3]. Furthermore, selective abortion is successfully done if foetal sex determination is done early in pregnancy. Foetal position is identified through auscultation which may be done in late pregnancy hence shield the foetus from selective abortion.

In such, the study agrees with the gynaecologist who advocate for determining foetal sex in late pregnancy to avoid "temptations" of abortion [10]. Therefore the increase of male ratio as revealed in this study may be termed as "natural sex ration" as it disagrees with the speculation of selective abortion and technology assistance. The revelation by the study that majority of babies who had adopted right occipital anterior position were female (74.4\%) whereas those who adopted left occipital anterior position were male (57.4\%) may suggest a relationship between sex of the baby and its in utero position.

Though no literature has been found relating foetal position and sex of the baby, this study could be likened to some sex prediction test such as the use of foetal heart rate. The method relies on heart rate of the foetus to predict it sex, with increased foetal heart rate predicting female while low foetal heart rate predicting male [4]. Whereas the foetal heart rate sex prediction test relies on increased or reduced foetal heart rate to predict the sex of the baby, this study has suggested the use of position of the foetus which is determined by foetal heart rate.

Though the accuracy of this method may not be determined, it is non-invasive, no associated risk, no cost involved and it may reduce selective abortion. Thus we agree with [11], that prenatal sex determination has high accuracy in invisible procedures compared to other methods. This also agrees with other studies which found that women avoid some methods of contraception that are believed to interfere with foetal positions [15] [16] [17] [18].

\section{Conclusion}

It follows then that sex of the baby may be related to the foetal position. This knowledge may be used by the midwives to predict the foetal sex for the women who may not afford ultrasound scan. Further research may be necessary in a different setting.

\section{Author Contributions}

ML conceptualised the study and obtained ethical approval, collected data and 
analysed; $\mathrm{CK}$ and ML interpreted the data; $\mathrm{CK}$ drafted and finalised the manuscript. The final manuscript was approved by the two authors.

\section{Conflicts of Interest}

The authors declare no conflicts of interest regarding the publication of this paper.

\section{References}

[1] Mcdermott, R. and Hatemi, P.K. (2011) Distinguishing Sex and Gender. Political Science and Politics, 44, 89-92. https://doi.org/10.1017/S1049096510001939

[2] Mcfadzen, M., Dielentheis, D.P., Kasten, R., Singh, M. and Grundle, J. (2017) Maternal Intuition of Fetal Gender. Journal of Patient-Centered Research and Reviews, 4, 125-130. https://doi.org/10.17294/2330-0698.1454

[3] Mohapatra, S. (2013) Global Legal Responses to Prenatal Gender Identification and Sex Selection. Vol. 690.

[4] Chalbi, M. (2015) How Many Parents to Be Want to Know the Baby's Sex. Published Online at Five Thirty Eight.

https://fivethirtyeight.com/features/how-many-parents-to-be-want-to-know-the-ba bys-sex/

[5] Ezugworie, J.O., Agu, A.U. and Onah, C.N. (2016) Prenatal Ultrasound Sex Identification: Some Factors That Influence Pregnant Women's Requests in Enugu, South-East Nigeria. Journal of Experimental and Clinical Anatomy, 15, 107-110. https://doi.org/10.4103/1596-2393.200913

[6] Larsson, M., Berglund, M., Jarl, E. and Tydén, T. (2018) Do Pregnant Women Want to Know the Sex of the Expected Child at Routine Ultrasound and Are They Interested in Sex Selection? Upsala Journal of Medical Sciences, 122, 1-6. https://doi.org/10.1080/03009734.2017.1408723

[7] Shukar-ud-din, S., Ubaid, F., Shahani, E. and Saleh, F. (2013) Reasons for Disclosure of Gender to Pregnant Women during Prenatal Ultrasonography. International Journal of Women's Health, 5, 781-785. https://doi.org/10.2147/IJWH.S40685

[8] Ikeako, L., Ezegwui, H., Onwudiwe, E. and Jo, E. (2014) Attitude of Expectant Mothers on the Use of Ultrasound in Pregnancy in a Tertiary Institution in South East of Nigeria. Annals of Medical and Health Sciences Research, 4, 949-953. https://doi.org/10.4103/2141-9248.144923

[9] Maaji, S., Ekele, B., Bello, S. and Morhason-Bello, I. (2010) Do Women Want Disclosure of Fetal Gender during Prenatal Ultrasound Scan? Annals of African Medicine, 9, 11-14. https://doi.org/10.4103/1596-3519.62618

[10] Nation (2007) Demand to Know Sex of Unborn Rising. Horizon. https://nation.africa/kenya/life-and-style/horizon/demand-to-know-sex-of-unbornrising-534538

[11] Gharekhanloo, F. (2018) The Ultrasound Identification of Fetal Gender at the Gestational Age of 11-12 Weeks. Journal of Family Medicine and Primary Care, 7, 210-212. https://doi.org/10.4103/jfmpc.jfmpc_180_17

[12] Robak-Chołubek, D., Chołubek, G. and Piróg, E. (2015) Determining Fetal Sex in Pregnancy with Reference to Pregnant Women Behavior in Late Pregnancy. Polish Journal of Public Health, 125, 87-89. https://doi.org/10.1515/pjph-2015-0030

[13] Ikechebelu, J.I. (2015) Palm Crease Marking: Can It Predict the Sex of the Next 
Child. West African Journal of Assisted Reproduction, 1, 1-4.

[14] Sarmah, H.K., Hazarika, B.B. and Choudhury, G. (2013) An Investigation on Effect of Bias on Determination of Sample Size on the Basis of Data Related to the Students of Schools of Guwahati. International Journal of Applied Mathematics \& Statistical Sciences, 2, 33-48.

[15] Kirigia, C., Gitonga, L.K. and Muraya, M.M. (2019) Barriers to Immediate Post-Partum Intra-Uterine Contraceptive Device Uptake among Mothers Delivering at Meru Hospital. Open Journal of Obstetrics and Gynecology, 9, 312-325. https://doi.org/10.4236/ojog.2019.93032

[16] Kirigia, C., Gitonga, L. and Muraya, M.M. (2019) Facilitators to Immediate Post Partum Intra Uterine Contraceptive Device Uptake among Mothers Delivering in Meru Hospital. Open Journal of Obstetrics and Gynecology, 9, 417-441. https://doi.org/10.4236/ojog.2019.94042

[17] Kirigia, C. (2018) fcs496. Barriers to Immediate Post-Partum Intrauterine Contraceptive Device (ppiud) Uptake among Post-Natals.

[18] Kirigia, C., Gitonga, L. and Muraya, M. (2019) Determinants of Immediate Post Partum Intrauterine Contraceptive Device Uptake among Mothers Delivering in Meru Hospital. Open Journal of Obstetrics and Gynecology, 9, 417-441.

https://doi.org/10.4236/ojog.2019.94042 